\title{
Semaphorin-4C is upregulated in epithelial ovarian cancer
}

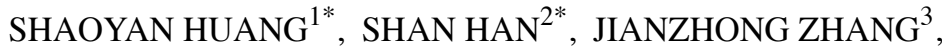 \\ ZHAOKUN ZHONG ${ }^{1}$ and JIANRONG WANG ${ }^{4}$
}

\author{
${ }^{1}$ Department of Oncology, Yantaishan Hospital, Yantai, Shandong 264000; ${ }^{2}$ Department of Oncology, \\ Dongying People's Hospital, Dongying, Shandong 257091; ${ }^{3}$ Department of Anesthesia, Yantaishan Hospital, Yantai, \\ Shandong 264000; ${ }^{4}$ Department of Obstetrics and Gynecology, Dongying People's Hospital, \\ Dongying, Shandong 257091, P.R. China
}

Received January 7, 2019; Accepted November 1, 2019

DOI: $10.3892 / 01.2020 .11444$

\begin{abstract}
The present retrospective study aimed to investigate the expression of semaphorin-4C (Sema4C) in epithelial ovarian cancer (EOC), and to determine the association between Sema4C expression and patient clinicopathological characteristics. Sema4C mRNA expression was detected by reverse transcription-quantitative polymerase chain reaction in the tissues of 74 cases of EOC, 20 cases of ovarian epithelial benign tumor, 20 cases of ovarian borderline epithelial tumor and 15 cases of normal ovarian tissue. Immunohistochemistry was used to detect the expression and localization of Sema4C. The association between Sema4C expression level and patients clinicopathological characteristics was determined by $\chi^{2}$ test. The results demonstrated that Sema4C expression level in ovarian epithelial carcinoma tissues was significantly higher compared with that in benign tumors, borderline epithelial tumors and normal ovarian tissues $(\mathrm{P}<0.05)$. In addition, Sema4C expression in ovarian cancer tissues was significantly associated with the clinical and pathological stages of tumors $(\mathrm{P}<0.05)$. In conclusion, the present study demonstrated that Sema4C expression was upregulated in EOC.
\end{abstract}

\section{Introduction}

Ovarian cancer is a common gynecological malignancy that has the highest mortality rate among all cancer types affecting women worldwide, with $>200,000$ new cases each year (1). Ovarian cancers are histologically defined as

Correspondence to: Dr Jianrong Wang, Department of Obstetrics and Gynecology, Dongying People's Hospital, 317 South East Road, Dongying, Shandong 257091, P.R. China

E-mail: jianrongwang006@163.com

\section{${ }^{*}$ Contributed equally}

Key words: semaphorin-4C, epithelial ovarian cancer, clinical pathology type I or type II. Type I refers to a relatively low histological grade, including endometrioid, mucinous and clear-cell carcinomas, whereas type II refers to a higher histological grade, including serous carcinoma and carcinosarcoma (2). Epithelial ovarian cancer (EOC) is the main type of ovarian cancer and represents $>90 \%$ cases. In addition, $\sim 90 \%$ of patients dying from EOC suffer from type II EOC (3). Treatment for ovarian cancer usually includes a combination of surgery, radiation therapy and chemotherapy (4). However, the outcome of patients depends also on their clinicopathological characteristics, including the subtype of ovarian cancer and the presence of other medical conditions (5). In addition to the aforementioned conventional treatments, targeted therapy, also known as molecularly targeted therapy, is one of the major treatment options, which only targets cancer cells (6). Targeted therapy may therefore be considered as a promising cure for patients with ovarian cancer in the near future.

Semaphorins are members of a family of membrane-bound and secreted molecules, which were originally identified as evolutionarily conserved axon-guidance cues in the human neural circuitry $(7,8)$. The semaphorin family is divided into eight classes, which consist of $>30$ genes, while the number of semaphorins is still rising. The neuropilin and plexin gene families encode the main semaphorin receptors (9). It has been widely reported that semaphorins are highly expressed in the human nervous system. For example, previous studies demonstrated that certain semaphorin members, including semaphorins $6 \mathrm{~B}$ and $5 \mathrm{~B}$, are involved in the progression of various types of cancer, including gastric cancer (10) and renal cell carcinoma (11). These semaphorins promote the progression and angiogenesis of tumor cells via numerous mechanisms, including the modulation of tumor angiogenesis $(10,11)$. Furthermore, certain semaphorins, including class 3 semaphorins, have been reported to inhibit tumor progression, whereas others, inducing semaphoring 4D, were demonstrated to promote tumor progression (9). To the best of our knowledge, there is no study about the expression of semaphorin-4C (Sema4C) in EOC.

Therefore, the present study investigated the expression of Sema4C in EOC and determined its association with the clinicopathological characteristics of patients with EOC. 


\section{Materials and methods}

Patients and tumor samples. EOC cancer tissues were obtained from patients who were surgically treated at the Department of Oncology of Yantaishan Hospital (Yantai, China) between January 2013 and January 2018. Cancer tissues were obtained within $30 \mathrm{~min}$ of the resection, placed in liquid nitrogen and stored at $-80^{\circ} \mathrm{C}$. In total, 74 cases of EOC, 20 cases of ovarian epithelial benign tumor, 20 cases of ovarian borderline epithelial tumor and 15 cases of normal ovarian tissues were collected. The age distribution of patients with EOC was 29-67 years (mean age, 51.2 \pm 7.6 years). The age distribution of patients with ovarian epithelial benign tumor was 30-68 years (mean age, $47.2 \pm 7.7$ years). The age distribution of patients with ovarian borderline epithelial tumor was 28-61 years (mean age, $43.6 \pm 6.8$ years). The age distribution of patients with normal ovarian tissues was 30-63 years (mean age, 45.6 \pm 7.4 years). The patients had no heart-, liver-, lung-, kidney- or other important organ-related diseases, and had no history of chemotherapy, radiotherapy or other treatment prior to surgery. Patients with other malignant tumors were also excluded.

The 74 cases with EOC were graded according to the World Health Organization (WHO) standards for histopathological clinical staging (12) as follows: A total of 44 patients had stages I and II EOC, whereas 30 patients had stage III EOC. However, according to the Union for International Cancer Control (UICC) standards (13), 21 cases were in stages I-II, whereas 53 cases were in stages III-IV. In total, 55 patients out of the 74 cases were $>50$ years old, and 49 out of the 74 patients presented with ascites.

EOC cancer tissues were obtained from patients who were surgically treated at the Department of Oncology of Yantaishan Hospital (Yantai, China) between January 2013 and January 2018 and who were diagnosed with EOC. The tissues previously mentioned were part of these tissues. In total, 111 EOC tissues were collected and embedded in paraffin before analyzing Sema $4 \mathrm{C}$ protein expression. According to the WHO standards for histopathological clinical staging, 69 cases were in stages I and II, whereas 44 cases were in stage III. However, according to the UICC standards, 29 cases were in stages I-II, whereas 82 cases were in stages III-IV. In total, 84 patients were $>50$ years old and 75 patients presented with ascites. The clinical data of all the patients were complete, and the pathological data were provided by a physician in-chief from the Pathology department of Yantaishan Hospital.

Reverse transcription-quantitative polymerase chain reaction $(R T-q P C R)$. Total RNA was extracted from tissues using TRIzol $^{\circledR}$ reagent (Invitrogen; Thermo Fisher Scientific, Inc.), and RNA purity was determined by calculating the $260 / 280$ ratio of optical densities using a nucleic acid-protein detector (DU-640; Beckman Coulter, Inc.). The result was between 1.8 and 2.0, which indicated sufficient RNA purity. cDNA was synthesized using an Eppendorf PCR Mastercycler (Eppendorf) according to the manufacturer's instructions, whereas qPCR was performed using SYBR-Green Master Mix (Applied Biosystems; Thermo Fisher Scientific, Inc.) and the GeneAmp 5700 Sequence Detector (Applied Biosystems; Thermo Fisher Scientific, Inc.). PCRs were performed as follows: $94^{\circ} \mathrm{C}$, melting under pre-denaturation for $5 \mathrm{~min} ; 94^{\circ} \mathrm{C}$ for additional $30 \mathrm{sec}, 72^{\circ} \mathrm{C}$ for $45 \mathrm{sec}$ and $62^{\circ} \mathrm{C}$ for $30 \mathrm{sec}$ (all steps were repeated for 35 cycles); and maintenance at $72^{\circ} \mathrm{C}$ for $10 \mathrm{~min}$. The primer sequences for Sema4C were synthesized by Shanghai GenePharma Co., Ltd. and were as follows: Sema4C, forward, 5'-ACCTTGTGCCGCGTAAGACAG-3' and reverse, 5'-CGTCAGCGTCAGTGTCAGGAA-3'; and $\beta$-actin, forward, 5'-CCTGGGCATGGAGTCCTGTG-3' and reverse, 5'-AGGGGCCGGACTCGTCATAC-3'. The relative expressions level of Sema4C was normalized to the endogenous control $\beta$-actin and was expressed as $2^{-\Delta \Delta C q}$ (14).

Immunohistochemistry (IHC) staining. Tissue sections from paraffin-embedded cancer tissues were incubated at $60^{\circ} \mathrm{C}$ for $30 \mathrm{~min}$, dewaxed using xylene and rehydrated using a decreasing ethanol gradient $(100,95,75$ and 50\%, 5 min each time). Sections were washed three times for 5 min with PBS. Sections were incubated in $3 \% \mathrm{H}_{2} \mathrm{O}_{2}$ dissolved in $80 \%$ methanol at room temperature for $10 \mathrm{~min}$ to inactivate endogenous peroxidase. Tissues were heated at $95^{\circ} \mathrm{C}$ for $20 \mathrm{~min}$ and blocked with 5\% bovine serum albumin (cat. no. B2064; Sigma-Aldrich; Merck KGaA) for $20 \mathrm{~min}$. Tissues were then incubated with rabbit polyclonal human primary antibody against Sema4C (1:400; cat. no. PA5-52788; Thermo Fisher Scientific, Inc.) at $4^{\circ} \mathrm{C}$ overnight, and incubated with goat anti-rabbit IgG secondary antibody (1:1,000; MH1732; Thermo Fisher Scientific, Inc.) at $37^{\circ} \mathrm{C}$ for $20-30 \mathrm{~min}$. Signals were visualized using $3^{\prime}$-diaminobenzidine staining (cat. no. TA-060-QHDX; Thermo Fisher Scientific, Inc.) at $37^{\circ} \mathrm{C}$ for $5-10 \mathrm{~min}$ and hematoxylin counterstained at $37^{\circ} \mathrm{C}$ for $30 \mathrm{sec}-1 \mathrm{~min}$. Differentiation was induced by hydrochloric acid and ethanol dehydration (80, 95 and 100\%, 5 min each time). For each slice, images of 10 sections were acquired under an optical microscope (BX45-72H05; Olympus Corporation; magnification, $x 100)$ to count positively stained cells. A percentage of positively stained cells $>30 \%$ was considered as a positive staining.

Statistical analysis. SPSS version 13.0 statistical software (SPSS Inc.) was used to statistically analyze the data. The results were expressed as the means \pm standard deviation. The t-test was used for comparisons between two datasets, whereas one-way analysis of variance followed by least-significant difference post hoc test was used for comparisons among multiple datasets. $\mathrm{P}<0.05$ was considered to indicate a statistically significant difference. The Sema4C protein expression levels were compared between groups using $\chi^{2}$ test. The correction between Sema4C mRNA level and Sema $4 \mathrm{C}$ protein expression were analyzed by Pearson's correlation analysis.

\section{Results}

Sema4C is upregulated in EOC tissues. The results from RT-qPCR demonstrated that Sema4C expression level was significantly higher in malignant tissues compared with that in borderline, benign and normal tissues $(\mathrm{P}<0.001$; Table I). In addition, the 74 cases of EOC were divided into four groups as follows: Serous carcinoma, mucinous adenocarcinoma, endometrial cancer uterus and clear cell carcinoma (Table I). 
Table I. Sema4C mRNA expression in different ovarian tissues.

\begin{tabular}{lccc}
\hline Variable & Number & Sema4C mRNA $(\bar{x} \pm$ SD $)$ & T-value \\
\hline Category & & & \\
$\quad$ Malignant & 74 & $0.0505 \pm 0.0308$ & 34.193 \\
Borderline & 20 & $0.0074 \pm 0.0113$ & $<0.001$ \\
Benign & 20 & $0.0059 \pm 0.0072$ & 1.012 \\
Normal & 15 & $0.0440 \pm 0.0212$ & $>0.05$ \\
Histological type & & $0.0595 \pm 0.0444$ & \\
Serous carcinoma & 24 & $0.0497 \pm 0.0295$ & $0.0501 \pm 0.0282$ \\
Mucinous adenocarcinoma & 21 & 15 & \\
Endometrial cancer uterus & 14 & & \\
Clear cell carcinoma & 15 & & \\
\hline
\end{tabular}

SD, standard deviation; Sema4C, semaphorin-4C.
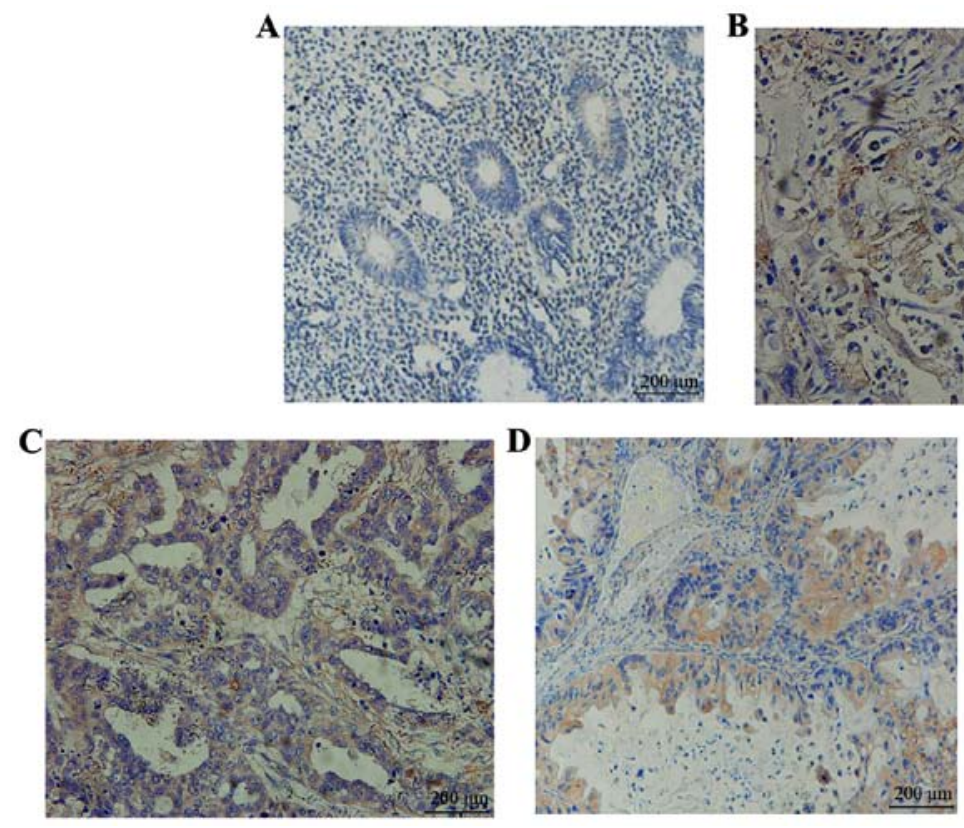

Figure 1. Immunohistochemical staining of ovarian tissues. Representative images of (A) normal ovarian tissue, (B) ovarian clear cell carcinoma tissue, (C) endometrioid ovarian cancer tissue, (D) mucinous ovarian cancer tissue and (E) serous ovarian cancer tissue. Magnification, x100.

These results indicated that Sema4C was highly expressed in all cancer tissues, but its expression level was not associated with the histological type $(\mathrm{P}>0.05)$.

To examine the expression of Sema4C protein in ovarian cancer, IHC was used. The results demonstrated that Sema4C protein was hardly expressed in the normal ovarian tissue (Fig. 1A), whereas it was highly expressed in EOC tissues (Fig. 1B-E). These findings confirmed that Sema4C mRNA and protein expression were highly expressed in EOC tissues.

Sema4C expression is associated with differentiation and clinical stage of EOC tissues. The association between Sema4C mRNA expression and numerous factors was analyzed, including cancer differentiation level, clinical stage, EOC ascites and age of the patients at disease onset. The results demonstrated that Sema4C mRNA expression
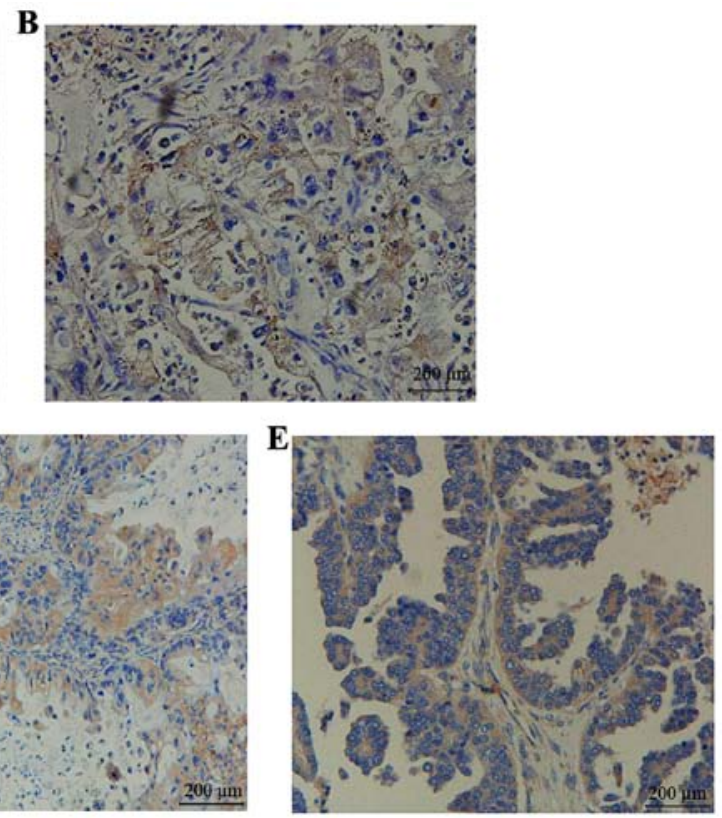

was significantly higher in the medium/high differentiation group compared with that in the low differentiation group ( $\mathrm{P}=0.011$; Table II). Furthermore, Sema4C mRNA expression in stages III and IV of ovarian cancer was significantly higher than that in stages I and II $(\mathrm{P}=0.014)$. These results indicated that Sema4C mRNA expression in EOC was associated with tissue differentiation, FIGO stage and ascites.

Furthermore, the association between Sema4C protein and clinicopathological factors was investigated, including histological type, ascites, age, differentiation and FIGO stage (Table III). The results demonstrated that Sema4C protein positive expression in the medium/highly-differentiated group (75.0\%) was significantly higher compared with that in the low differentiation group $(52.2 \% ; \mathrm{P}=0.016)$. In addition, Sema4C protein positive expression in tissues at clinical stages III-IV $(68.3 \%)$ was also significantly increased compared with that at 
Table II. Association between Sema4C mRNA expression and clinicopathological features of patients with epithelial ovarian cancer.

\begin{tabular}{|c|c|c|c|c|}
\hline Variable & Number & $\operatorname{Sema} 4 \mathrm{C}$ mRNA $(\bar{x} \pm \mathrm{SD})$ & T-value & P-value \\
\hline \multicolumn{5}{|l|}{ Differentiation } \\
\hline Low & 44 & $0.0431 \pm 0.0238$ & 2.598 & 0.011 \\
\hline Medium/high & 30 & $0.0614 \pm 0.0367$ & & \\
\hline \multicolumn{5}{|l|}{ FIGO stage } \\
\hline I-II & 21 & $0.0367 \pm 0.0236$ & 2.527 & 0.014 \\
\hline III-IV & 53 & $0.0560 \pm 0.0318$ & & \\
\hline \multicolumn{5}{|l|}{ Ascites } \\
\hline Yes & 49 & $0.0536 \pm 0.0331$ & 1.213 & 0.229 \\
\hline No & 25 & $0.0445 \pm 0.0253$ & & \\
\hline \multicolumn{5}{|l|}{ Age, years } \\
\hline$<50$ & 19 & $0.0467 \pm 0.0279$ & -6.332 & 0.529 \\
\hline$\geq 50$ & 55 & $0.0519 \pm 0.0319$ & & \\
\hline
\end{tabular}

SD, standard deviation; Sema4C, semaphorin-4C; FIGO, International Federation of Gynecology and Obstetrics.

Table III. Association between semaphoring-4C protein expression and clinicopathological characteristics of patients with ovarian cancer.

\begin{tabular}{|c|c|c|c|c|}
\hline Variable & Positive, n (\%) & Negative, n (\%) & $\chi^{2}$ & P-value \\
\hline \multicolumn{5}{|l|}{ Histological type } \\
\hline Serous carcinoma & $16(53.3)$ & $14(46.7)$ & 2.907 & 0.406 \\
\hline Mucinous adenocarcinoma & $22(73.3)$ & $8(26.7)$ & & \\
\hline Endometrial cancer uterus & $17(56.7)$ & $13(43.3)$ & & \\
\hline Clear cell carcinoma & $13(61.9)$ & $8(38.1)$ & & \\
\hline \multicolumn{5}{|l|}{ Ascites } \\
\hline Yes & $49(65.3)$ & $26(34.7)$ & 1.616 & 0.204 \\
\hline No & $19(52.8)$ & $17(47.2)$ & & \\
\hline \multicolumn{5}{|l|}{ Age, years } \\
\hline$<50$ & $14(56.0)$ & $11(44.0)$ & 0.376 & 0.540 \\
\hline$\geq 50$ & $54(62.8)$ & $32(37.2)$ & & \\
\hline \multicolumn{5}{|l|}{ Differentiation } \\
\hline Low & $35(52.2)$ & $32(47.8)$ & 5.798 & 0.016 \\
\hline Medium/high & $33(75.0)$ & $11(25.0)$ & & \\
\hline \multicolumn{5}{|l|}{ FIGO stage } \\
\hline I-II & $12(41.4)$ & $17(58.6)$ & 6.539 & 0.011 \\
\hline III-IV & $56(68.3)$ & $26(31.7)$ & & \\
\hline
\end{tabular}

FIGO, international federation of gynecology and obstetrics.

clinical stages I-II $(41.4 \% ; \mathrm{P}=0.011)$. These findings indicated that Sema4C protein expression was associated with the differentiation and FIGO stage of EOC, but not with histological type, ascites and age $(\mathrm{P}>0.05)$.

Sema4C is upregulated in late-stage EOC. The positive expression rate of Sema4C in EOC tissues was $61.3 \%$ (Table IV), whereas the values for borderline ovarian epithelial tumor, benign tumor and normal ovarian tissues were 26.7, 16.7 and
$10.0 \%$, respectively. The results of $\chi^{2}$ test demonstrated that the positive expression rate of Sema4C in EOC tissues was significantly higher compared with that in the other three types of tissue $(\mathrm{P}<0.01$; Table IV).

The results from Pearson's correlation analysis (Table V) revealed that Sema4C mRNA expression and Sema4C protein expression in EOC tissues were positively correlated $(\mathrm{P}<0.01)$. The regression equation was $\mathrm{Y}=-1.50814+1.052126 \mathrm{X}$, with a correlation coefficient of $\mathrm{R}^{2}=0.955(\mathrm{P}<0.01)$. Furthermore, 
Table IV. Expression of semaphorin-4C protein in different categories of ovarian tissue.

\begin{tabular}{|c|c|c|c|c|}
\hline Category & Positive, n (\%) & Negative, n (\%) & $\chi^{2}$ & P-value \\
\hline Malignant & $68(61.3)$ & $43(38.7)$ & 40.367 & $<0.01$ \\
\hline Borderline & $8(26.7)$ & $22(38.7)$ & & \\
\hline Benign & $5(16.7)$ & $25(83.3)$ & & \\
\hline Normal & $3(10.0)$ & $27(90.0)$ & & \\
\hline
\end{tabular}

Table V. Pearson's correlation analysis between the mRNA and protein expression of Sema4C.

\begin{tabular}{lccr}
\hline Sema4C expression & Positive, $n(\%)$ & Negative, $\mathrm{n}(\%)$ & $\mathrm{R}^{2}$ \\
\hline mRNA & $44(59.46)$ & $30(40.54)$ & P-value \\
Protein & $68(61.26)$ & $43(38.74)$ & 0.955 \\
\hline
\end{tabular}

Sema4C, semaphorin-4C.

the results from Pearson's correlation analysis revealed that Sema4C mRNA expression and Sema4C positive expression rate were positively correlated with tumor malignancy and clinical stage.

\section{Discussion}

Semaphorins were originally reported as serving crucial role in nervous system $(10,15,16)$. Over the past decade, semaphorins have been thought to be involved in numerous developmental processes, including cell migration and invasion (15-18). In particular, Sema3B and Sema3F were successfully identified as modulators of tumor progression $(17,18)$. In addition to these two semaphorins, semaphorins $6 \mathrm{~B}$ has been characterized as regulators of tumor progression (10). To the best of our knowledge, the present study was the first to confirm that both Sema4C mRNA and protein expression were highly expressed in EOC tissues. Furthermore, Sema4C mRNA expression in EOC was associated with tissue differentiation, FIGO stage and ascites. Sema4C protein expression was also found to be upregulated in late-stage EOC.

Class 4 semaphorins are single-pass transmembrane proteins that usually exert clear influences on tumor progression. For example, Sema4D was demonstrated to be upregulated in several types of cancer, including head and neck, cervical, colon, prostate, lung and breast cancer (19). In addition, Sema4C is expressed at a relatively low rate $(3.3 \%)$, or not at all in normal ovarian tissues, which was similar to the findings of the present study. In the present study, Sema4C protein was expressed at a low rate $(3.0 \%)$ in normal ovary. In addition, Sema4C protein was positively expressed in EOC $(56.0 \%)$, and was mostly located in the cytoplasm and/or cell membrane.

A previous study reported that Sema4C stimulates the production of angiogenin and colony-stimulating factor-1 in breast cancer cells by activating the NF- $\mathrm{B}$ signaling pathway (20). Furthermore, Gurrapu et al (21) reported that Sema4C/PlexinB2 signaling pathway was essential for breast carcinoma cell proliferation, suggesting that it might be considered as a novel potential therapeutic target. In addition, it was reported that elevated Sema4C expression enables indolent luminal-type tumors to become resistant to estrogen deprivation, invasive and metastatic in vivo. The present study reported that Sema4C was highly expressed in ovarian epithelial cancer tissues; however, the underlying mechanisms remain clear. The role of Sema4C in the stimulation of ovarian epithelial cancer growth requires therefore further investigation.

In conclusion, the present study demonstrated that Sema4C was highly expressed in EOC tissues, and that Sema4C mRNA and protein expression were associated with tumor malignancy and clinical stage. These findings suggested that high Sema4C expression in EOC tissues may be associated with poor prognosis in patients with EOC.

\section{Acknowledgements}

Not applicable.

\section{Funding}

The present study was funded by the Key Research and Development Plan in Shandong Province (grant no. 2018GSF118054).

\section{Availability of data and materials}

The datasets used and/or analyzed during the current study are available from the corresponding author on reasonable request.

\section{Authors' contributions}

SYH, SH and JW participated in the design of the study. SYH, $\mathrm{SH}, \mathrm{JZ}$ and ZZ carried out RT-qPCR and IHC experiments and performed statistical analysis. SYH drafted the manuscript. All authors read and approved the final version of the manuscript. 


\section{Ethics approval and consent to participate}

The present study was approved by the Ethics Committee of the Yantaishan Hospital and all patients provided written informed consent (clinical trial no. ChiCTR1900020785).

\section{Patient consent for publication}

Not applicable.

\section{Competing interests}

The authors declare that they have no competing interests.

\section{References}

1. Funston G, Van Melle M, Bain ML, Jensen H, Helsper C, Emery J, Crosbie EJ, Thompson M, Hamilton W and Walter FM: Variation in the initial assessment and investigation for ovarian cancer in symptomatic women: A systematic review of international guidelines. BMC Cancer 19: 1028, 2019.

2. Previs R, Leath CA 3rd, Coleman RL, Herzog TJ, Krivak TC, Brower SL, Tian C and Secord AA: Evaluation of in vitro chemoresponse profiles in women with type I and type II epithelial ovarian cancers: An observational study ancillary analysis. Gynecol Oncol 138: 267-271, 2015.

3. Nhokaew W, Kleebkaow P, Chaisuriya N and Kietpeerakool C: Programmed Death ligand (PD-L1) expression in epithelial ovarian cancer: A comparison of I and type II tumors. Aaian Pac J Cancer Prev 20: 1161-1169, 2019.

4. Modugno F and Edwards RP: Ovarian cancer: Prevention, detection, and treatment of the disease and its recurrence. Molecular mechanisms and personalized medicine meeting report. Int J Gynecol Cancer 22: S45-S57, 2012.

5. Webb PM and Jordan SJ: Epidemiology of epithelial ovarian cancer. Best Pract Res Clin Obstet Gynaecol 41: 3-14, 2017.

6. Grunewald T and Ledermann JA: Targeted therapies for ovarian cancer. Best Pract Res Clin Obstet Gynaecol 41: 139-152, 2017.

7. Alto LT and Terman JR: Semaphorins and their signaling mechanism. Methods Mol Biol 1493: 1-25, 2017.
8. Wei L, Li H, Tamagnone L and You H: Semaphorins and their receptors in hematological malignancies. Front Oncol 9: 382, 2019.

9. Neufeld G, Mumblat Y, Smolkin T, Toledano S, Nir-Zvi I, Ziv K and Kessler O: The semaphorins and their receptors as modulators of tumor progression. Drug Resist Updat 29: 1-12, 2016.

10. Ge C, Li Q, Wang $\mathrm{L}$ and $\mathrm{Xu} \mathrm{X}$ : The role of axon guidance factor semaphorin 6B in the invasion and metastasis of gastric cancer. J Int Med Res 41: 284-292, 2013.

11. Nenfeld G, Mumblat Y, Smolkin T, Toledano S, Nir-Zvi I, Ziv K and Kessler O: The role of the semaphorins in cancer. Cell Adh Migr 10: 652-674, 2016.

12. Word Health Organization (WHO) (2010); Treatment of tuberculosis: Guidelines. Fourth Edition.

13. Wittekind C and Sobin LH (eds): TNM Classification of Malignant Tumors. 5th edition. Wiley-Liss, New York, NY, 1997.

14. Livak KJ and Schmittgen TD: Analysis of relative gene expression data using real-time quantitative PCR and the 2(-Delta Delta C(T)) method. Methods 25: 402-408, 2001.

15. Vadasz Z, Rubinstein J, Bejar J, Sheffer H and Halachmi S: Overexpression of semaphorin $3 \mathrm{~A}$ in patients with urothelial cancer. Urol Oncol 36: 161 e1-161 e6, 2018.

16. Schaeffer J, Tannahill D, Cioni JM, Rowlands D and Keynes R: Identification of the extracellular matrix protein Fibulin-2 as a regulator of spinal nerve organization. Dev Biol 442: 101-114, 2018.

17. Kaitu'u-Lino TJ, Hastie R, Cannon P, Binder NK, Lee S, Stock O, Hannan NJ and Tong S: Placental SEMA3B expression is not altered in severe early onset preeclampsia. Placenta 35: 1102-1105, 2014.

18. Rao J, Zhou ZH, Yang J, Shi Y, Xu SL, Wang B, Ping YF, Chen L, Cui YH, Zhang X, et al: Semaphorin-3F suppresses the stemness of colorectal cancer cells by inactivating Rac1. Cancer Lett 358: 76-84, 2015.

19. Cao Z, Yu D, Fu S, Zhang G, Pan Y, Bao M, Tu J, Shang B, Guo P, Yang $\mathrm{P}$ and Zhou Q: Lycorine hydrochloride selectively inhibits human ovarian cancer cell proliferation and tumor neovascularization with very low toxicity. Toxicol Lett 218: 174-185, 2013.

20. Yang J, Zeng Z, Qiao L, Jiang X, Ma J, Wang J, Ye S, Ma Q, Wei J, Wu M, et al: Semaphorin 4C promotes macrophage recruitment and angiogenesis in breast cancer. Mol Cancer Res 17: 2015-2028, 2019.

21. Gurrapu S, Pupo E, Franzolin G, Lanzetti L and Tamagonoe L: Sema4C/PlexinB2 signaling controls breast cancer cell growth, hormonal dependence and tumorigenic potential. Cell Death Differ 25: 1259-1275, 2018. 